\title{
Computer ergonomics related health problems of Library staff: a case study at the University of Colombo
}

Anuja Silva ${ }^{1}$

\begin{abstract}
This paper discusses computer ergonomics related health problems caused by prolonged use of computers in the library staff of the University of Colombo. The heterogeneous population, 60 in total consisted of academic staff, administrative officers and paraprofessional staff including Senior Staff Assistants, Staff Assistants, Management Assistants and Library Information Assistants. A stratified random sampling technique was used to draw the sample (52). A questionnaire was administered to collect data. Data were analysed with descriptive statistics and correlation test using SPSS version 23. It revealed that neck pain was the major (63.8\%) musculoskeletal discomfort experienced by the respondents after prolonged period of computer usage followed by shoulder pain $(59.6 \%)$ and pain in the wrist $(53.2 \%)$. Pain in the eye $(76.6 \%)$ was the most persistent visual discomfort experienced by the respondents followed by headaches $(72.3 \%)$. Major stress-related problem was sleepiness $(51.1 \%)$ while loss of concentration was identified as the prominent discomfort related to fatigue (27.7\%). Prevalence of musculoskeletal discomforts such as pain in the neck and lower arm showed a positive correlation with the height of computer table $(\mathrm{r}=$ $0.447, \mathrm{P}=0.002$ and $\mathrm{r}=0.403, \mathrm{P}=0.005$ respectively), while shoulder pain indicated a weak negative correlation with wrist support $(\mathrm{r}=-0.317, \mathrm{P}=0.03)$. Data on prevalence of lower arm pain depicted a weak positive correlation with height and distance of the keyboard $(\mathrm{r}=0.384, \mathrm{P}=0.008)$ and computer desk height $(\mathrm{r}=0.403, \mathrm{P}=0.005)$. As for visual discomfort symptoms developing double vision had a weak positive correlation with glare $(\mathrm{r}$
\end{abstract}

\footnotetext{
${ }^{1}$ Senior Assistant Librarian, University of Colombo, Sri Lanka, email: anusilva@ @ib.cmb.ac.lk, (D) https://orcid.org/0000-0001-9345-7509
} 
$=0.315, \mathrm{P}=0.031)$ and a weak negative correlation with lighting in the workstation $(\mathrm{r}=-0.291, \mathrm{P}=0.046)$. Headaches due to extended use of computers showed a significant relationship with view distance $(\mathrm{P}=0.003)$ and task breaking $(\mathrm{P}=0.033)$. To avoid visual discomforts ergonomic requirement at the computer workstation should be proper lighting, anti-glare filters, and ergonomic positioning of computer monitor and regular work breaks. To reduce health problems, library management should organize workstation ergonomic training sessions to gain knowledge and skills required to optimize the workstation configuration, and provide ergonomically safe working equipment.

Keywords: Computer Ergonomics, Health Problems, Library Staff, Musculoskeletal Discomfort, Visual Discomfort, Stress, Fatigue

\section{Introduction}

The advent of Information Communication Technology has changed the fundamental practice and procedures of libraries to provide effective, efficient services to the clientele. Penetration of computers forced the library staff to work long hours in front of the computer for automation of library processes, searching for electronic resources, ordering library materials, database management and web page development. Incorrect use of computer for a prolonged period increases the risk of adverse health effects. Although, users of computers in libraries increase rapidly in number changes have not been accompanied for workstation design. Computer ergonomics is the discipline that addresses ways to optimize the computer workstation to reduce specific risks of computer vision syndrome, neck and back pain, carpal tunnel syndrome and other disorders affecting muscles, spine and joints. Poorly designed computer workstations and lack of awareness among computer users regarding ergonomic requirements trigger computer related health problems.

Ergonomics were given a major concern as patients suffering from musculoskeletal conditions increased globally by $25 \%$ over the past decades in which the majority were related to the use of computers (Karsh, Moro \& Smith, 2001). In European countries, numerous studies have been carried out on ergonomic health related issues. However, Asian countries are far behind their western counterparts in this aspect. There is a dearth of published 
studies on computer ergonomics of Sri Lankan university library setup and associated health issues and creates a gap in ergonomic literature. The ultimate focus of this study was to fill the existing gap. Identification of computer ergonomic related health issues will facilitate the library management to provide better workplace facilities to the staff thereby increase the efficiency by making the job fit to the worker instead of imposing the worker to conform to the job.

\section{Research Objectives}

The objective of this study was to identify the computer ergonomics related health issues of library staff of the University of Colombo and to provide recommendations to improve the workplace facilities.

Following pertinent hypotheses were formulated to support achieving the objectives;

\section{Hypotheses}

H0 1: There is no significant relationship between the computer ergonomics related health problems and socio-demographic characters of the library staff H0 2: There is no significant relationship between computer ergonomics related health problems and workstation design.

\section{Literature Review}

The literature on computer ergonomics associated health problems, working environment, equipment and design are depicted below.

\section{Computer Ergonomics Rlated Health Problems}

Numerous researchers (Suparna et al., 2005; Pillai \& Jayalatha, 2016; Ellahi et al., 2011) have studied about common ergonomic health issues caused by prolonged use of computers.

Computer vision syndrome is a collection of symptoms as eyestrain, tired eyes, irritation, redness, blurred vision, double vision and dry eyes due to staring at the computer for an extended period. The ergonomic requirement at the computer workstation to avoid computer vision syndrome includes proper lighting, anti-glare filters, and ergonomic positioning of the computer monitor and regular work breaks (Blehm et al., 2005). 
Musculoskeletal discomfort- Numerous studies have shown that computer users experienced musculoskeletal discomforts (Zakerian \& Subramanian, 2009; Pillai \& Jayalatha, 2016) which include pain in the neck, shoulder and back due to prolonged use of computers. A forearm support board (Conlon et al., 2008), an alternative computer keyboard as split, gabled keyboard design (Rempel et al., 2009) and an ergonomic chair can be used to minimize the musculoskeletal discomforts.

Stress- With prolonged use of computers for 30 hours per week somatic disorders, depression and obsession increased (Wang et al., 1998). Similar findings were revealed by Thomée et al. (2012) and reported that long hours of computer usage (more than 4 hours per day) without breaks were associated with perceived stress, sleep disturbances and symptoms of depression greater in women than men.

\section{Working Environment \& Equipment}

Ergonomic computer workstation enhances the standard of work in a library (Asaolu \& Itsekor, 2014). Workstation design includes the positioning of computers, desk, chair, space and layout.

The computer monitors should be positioned infront of the worker, perpendicular to the light sources (Adeyemi, 2010) and be at or below the eye level. There are discrepancies with the viewing distance of the monitors. However, the preferred viewing distance of a typical user is greater than 40 $\mathrm{cm}$ according to the ISO-9241(ISO, 1998).

The use of a proper chair is vital to minimize musculoskeletal disorders of the back, legs, buttocks and arms. Most of the ergonomic guidelines recommended that the height of the chair should permit feet to rest flat on the ground or a footrest. The chair should be height adjustable and it was recommended that the seat height is between 38 and $56 \mathrm{~cm}$, and the depth is between 33 and $48 \mathrm{~cm}$ (Woo et al., 2016). Backrest with height and inclination adjustable should provide adequate lumbar support. Presence of adjustable height and strength lumbar supports in office chairs are essential to minimize back strain. In the literature, a controversy exists regarding the 
requirement of the armrest in office chairs. However, the study conducted by Marcus et al. (2002) revealed that the presence of armrests in chairs reduced neck and shoulder disorders.

The height of the workstation is crucial to prevent musculoskeletal disorders of elbows, shoulders, hands and wrists. Guidelines stipulated that optimal work surface height should be fixed between 68 and $72 \mathrm{~cm}$, or adjustable between 56 and $76 \mathrm{~cm}$ (Woo et al., 2016). The positioning of the mouse and keyboard is also a vital factor to reduce musculoskeletal discomforts. Marcus et al. (2002) reported that the placement of a keyboard with a distance of more than $12 \mathrm{~cm}$ from the table edge is associated with a lower risk of hand and arm disorders.

A study conducted by Nwokedi et al. (2019) in a Nigerian academic library revealed that $50 \%$ of the library staff was not aware of the sitting posture and $58.33 \%$ on working posture of arms and wrist while working in the computer. Another study conducted in Nigerian libraries by Asaolu and Itsekor (2014) revealed that ergonomic health problems amongst the library staff were due to poorly designed seats, awkward posture, exposure to computers without screen protectors, sitting in the same posture for long hours and frequent repetitive motion tasks.

The survey conducted by Pillai and Jayalatha (2016) at the Kariavattom Campus, University of Kerala revealed that $59 \%$ of the library professionals were suffering from pain in the lower arm and wrist and 65\% experiencing vision problems like blurred or double vision, tearing, irritation in eyes and headaches. Furthermore, 66\% of library professionals were suffering from back pain, neck, upper back and shoulder rigidity due to prolonged use of computers and the authors recommended improving equipment and working environment. Adeyemi (2010) reported the most prevalent health problems of tension, stress, headaches, pain in the wrist, forearm, elbow, neck, or back encountered by the library staff of selected academic libraries in Nigeria were due to poorly designed seats and exposure to computer screens without protectors. The review of related literature on computer ergonomics and related health issues in the Sri Lankan academic libraries revealed a dearth of published studies. Therefore, the present study is conducted to fill the existing knowledge gap. 


\section{Methodology}

The staff structure of the Library system of the University of Colombo comprised of academic, administrative, paraprofessional and support staff. Library support staff was excluded from the present study as they do not extensively use computers to perform work. The heterogeneous staff structure with a total population of 60 includes 16 academic staff; 2 administrative officers and 42 paraprofessional staff comprising Senior Staff Assistants, Staff Assistants, Management Assistants and Library Information Assistants. Krejcie and Morgan's (1970) recommendations were adopted to maintain the sample size which was 52 , and a stratified random sampling technique was incorporated to draw the sample to represent each stratum from the entire population (Table 1). A structured questionnaire based on multidimensional scaling was administered in February, 2020 to collect data. The questionnaire embraced 47 questions which covered socio-demographic information, workstation configuration and ergonomic health related problems such as musculoskeletal and visual discomforts, stress and fatigue. A pilot study was conducted to observe adequacy of instruction and clarity of the format, and it made an important contribution specifically to provide clearer instructions. Reliability analysis was performed to measure the internal consistency of the questionnaire using Cronbach's Alpha Coefficient which was found to be 0.876 . The obtained data were analysed with descriptive statistics and correlation test using SPSS version 23 and significance was determined at 5\% level.

Table 1: Population and sample

\begin{tabular}{llcc}
\hline & Staff Structure & Population & Sample \\
\hline Academic staff & Librarian (L) & 1 & 1 \\
& Deputy Librarian (DL) & 1 & 1 \\
& Senior Assistant Librarian (SAL) & 7 & 6 \\
& Assistant Librarian (AL) & 7 & 6 \\
Administrative & Sub Total & $\mathbf{1 6}$ & $\mathbf{1 4}$ \\
officers & Senior Assistant Registrar (SAR) & 1 & \\
\multirow{3}{*}{ Para-professional } & Assistant Registrar (AR) & 1 & $\mathbf{1}$ \\
staff & Sub Total & $\mathbf{2}$ & $\mathbf{1}$ \\
& Senior Staff Assistant (SSA) & 5 & $\mathbf{4}$ \\
& Staff Assistant (SA) & 1 & 1 \\
& Library Information Assistant (LIA) & 35 & 31 \\
& Management Assistant (MA) & 1 & 1 \\
& Sub Total & $\mathbf{4 2}$ & $\mathbf{3 7}$ \\
& Total & $\mathbf{6 0}$ & $\mathbf{5 2}$ \\
\hline
\end{tabular}




\section{Results \& Discussion}

Valid responses were received by $90.38 \%$ and amongst them, the majority were female $(72.3 \%)$ in the age group of $31-40$ years $(61.7 \%)$. The employee's working hours with computers is vital to identify health issues related to computer ergonomics, and the present study revealed that the majority of respondents (83\%) spent 5-8 hours per day with computers during work and had used computers for 5-15 years (57.4\%).

\section{Computer Ergonomics Related Health Problems}

\section{Musculoskeletal discomforts}

The present study examined the prevalence of musculoskeletal discomforts such as pain in muscles, elbow, fingers, wrist, shoulder, neck, upper back, lower back and knee. It revealed that pain in the neck was the major musculoskeletal discomfort experienced by respondents (63.8\%) after prolonged period of computer usage followed by shoulder pain $(59.6 \%)$, wrist pain (53.2\%) and upper back pain (44.7\%). Pain in the elbow and knee were identified as the least $(27.7 \%)$ experienced musculoskeletal discomforts (Figure 1). Similar findings were discovered by James et al. (2018) and Griffiths et al. (2012) and revealed that neck pain and shoulder pain were the most prominent musculoskeletal discomforts suffered by the respondents. However, wrist pain was reported as the third prevalent musculoskeletal discomfort experienced by the library staff in this study and was congruent with the findings of Pillai and Jayalatha (2016) and negates with James et al. (2018).

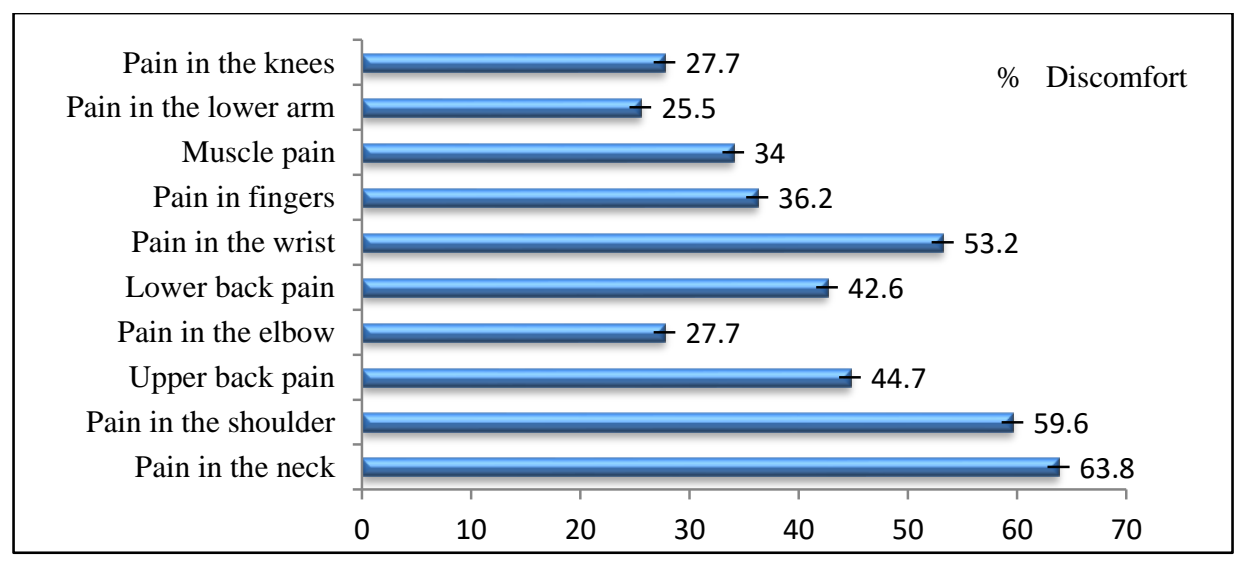

Figure 1: Percentage distribution of musculoskeletal discomforts 
Cross tabulation showed that experiencing pain in the neck was prominent in females $(76.7 \%)$ between the age group of 31-40 years (66.6\%) and working 5-8 hours/day (90\%) with computer (Table 2).

Table 2: Association between prevalence of musculoskeletal discomforts and sociodemographic characters

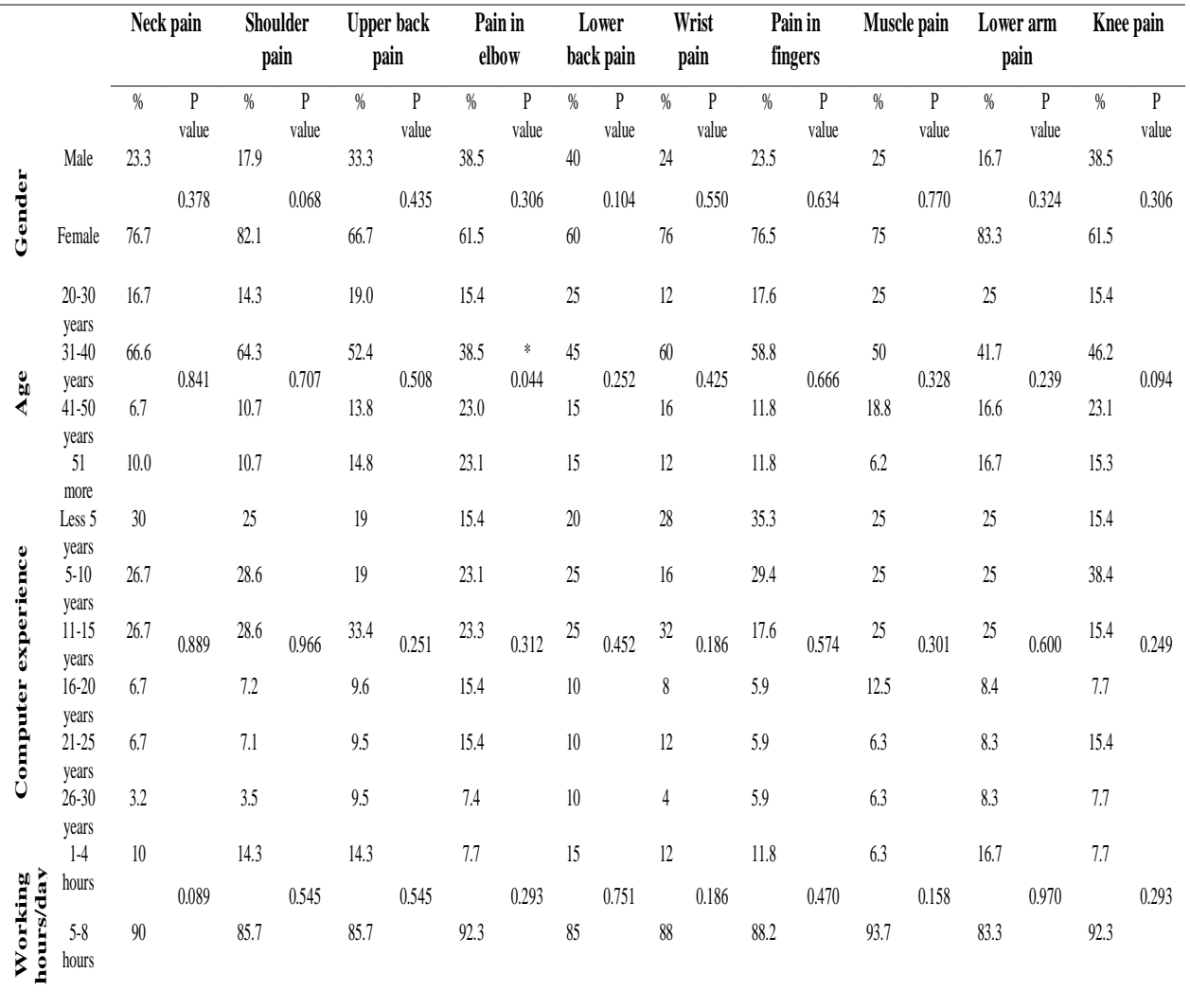

As depicted in Table 2, Chi-Square test proved that there is no significant relationship between reporting of pain in muscles, fingers, wrist, shoulder, neck, upper back, lower back, knee and gender, age, computer usage hours/ day and years of computer usage. However, it revealed that pain in the elbow had a significant relationship with age $(\mathrm{P}=0.044)$. According to the existing literature, females are more prone to musculoskeletal discomforts than males, and the findings of the present study was consistent with that of Oha et al. (2014). 


\section{Visual Discomfort}

Prevalence of visual discomforts was examined through complains of eye pain, double vision, blurred vision, tearing, burning eyes, dry eyes and headaches. It revealed that pain in the eye was the major visual discomfort experienced by the respondents $(76.6 \%)$ after prolonged period of computer usage followed by headaches $(72.3 \%)$. Double vision was identified as the least $(31.9 \%)$ prevailing visual discomfort. Findings of the present study was congruent with Iwakiri et al. (2004) who found that $72.1 \%$ of office workers having eye strain and/or pain.

Cross tabulation indicated that incidence of pain in the eye was prominent in females $(69.4 \%)$ between the age group of $31-40$ years $(58.3 \%)$ having computer usage experience less than 5 years (30.6\%) and working 5-8 hours/day (88.9\%) on the computer (Table 3).

Table 3: Association between prevalence of visual discomfort and socio-demographic

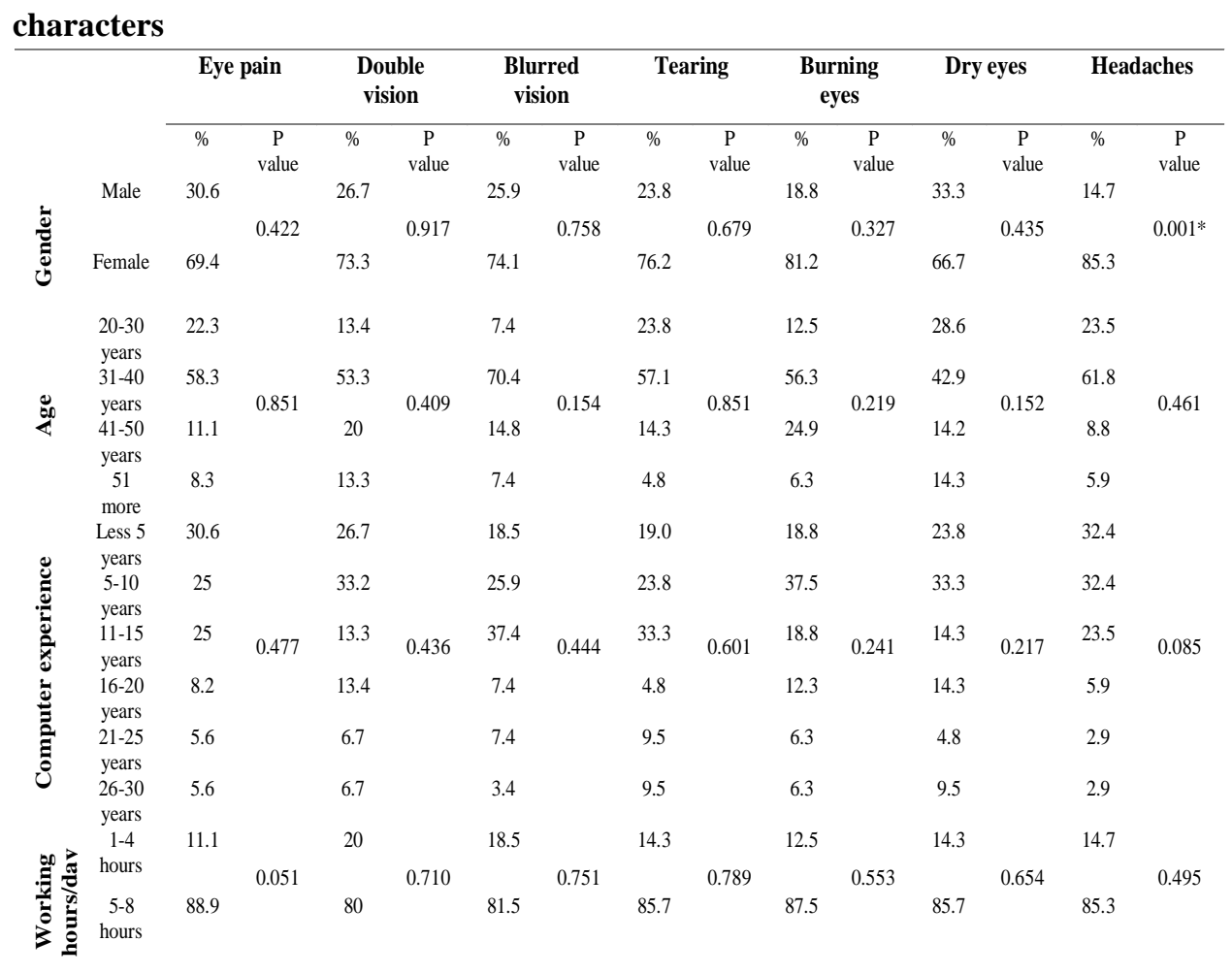


As depicted in Table 3, Chi-Square test revealed that reporting of eye pain, double vision, blurred vision, tearing, burning eyes and dry eyes had no significant relationship with gender, age, years of computer usage and working hours/day in the context of the study. Furthermore, Chi-square analysis revealed a significant relationship between gender and headaches $(\mathrm{P}=0.001)$ in the present study similar to the findings of Shantakumari et al. (2014). The findings of the present study are congruent with Rahman and Sanip (2011) who reported that female respondents using computers for prolonged time are more persistent to have computer vision problems.

\section{Stress \& Fatigue}

Stress related health issues due to prolonged use of computers were examined through reporting of sleepiness, anger and restlessness. As depicted in Figure $2 ; 51.1 \%$ of the respondents reported sleepiness and 17\% reported anger. Cross tabulation indicated that amongst the respondents who reported sleepiness while working in the computer, the majority were females $(79.2 \%)$ in the age group of 31-40 years (66.7\%) having used computers for 11-15 years $(37.5 \%)$ and working 5-8 hours/day $(87.5 \%)$ with computers. Chisquare analysis revealed a relationship between anger and age $(\mathrm{P}=0.031)$ while sleepiness and restlessness did not show any relationship with gender, age, computer experience and working hours/day (Table 4).

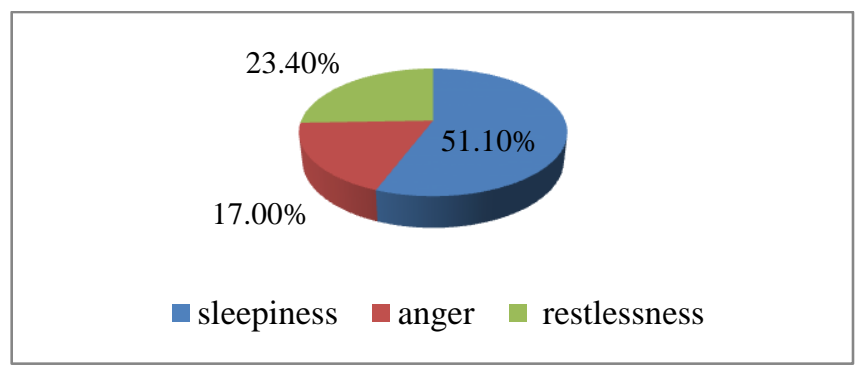

Figure 2: Distribution of stress

Fatigue or tiredness was examined through symptoms such as dizziness, loss of concentration and irritability. Loss of concentration (27.7\%) was identified as the major discomfort related to fatigue experienced by respondents after prolonged use of computers. Cross tabulation depicted that amongst the female respondents $(84.6 \%)$ in the age group of 31-40 years $(61.5 \%)$ with less than 5 years computer experience (46.2\%) and who worked for 5-8 hours/day with computers showed symptom of loss of concentration. Chi- 
square analysis revealed that there is no significant relationship between dizziness, loss of concentration and irritability with gender, age, computer experience or working hours/day (Table 4).

Table 4: Association between socio-demographic characters and prevalence of Stress / Fatigue

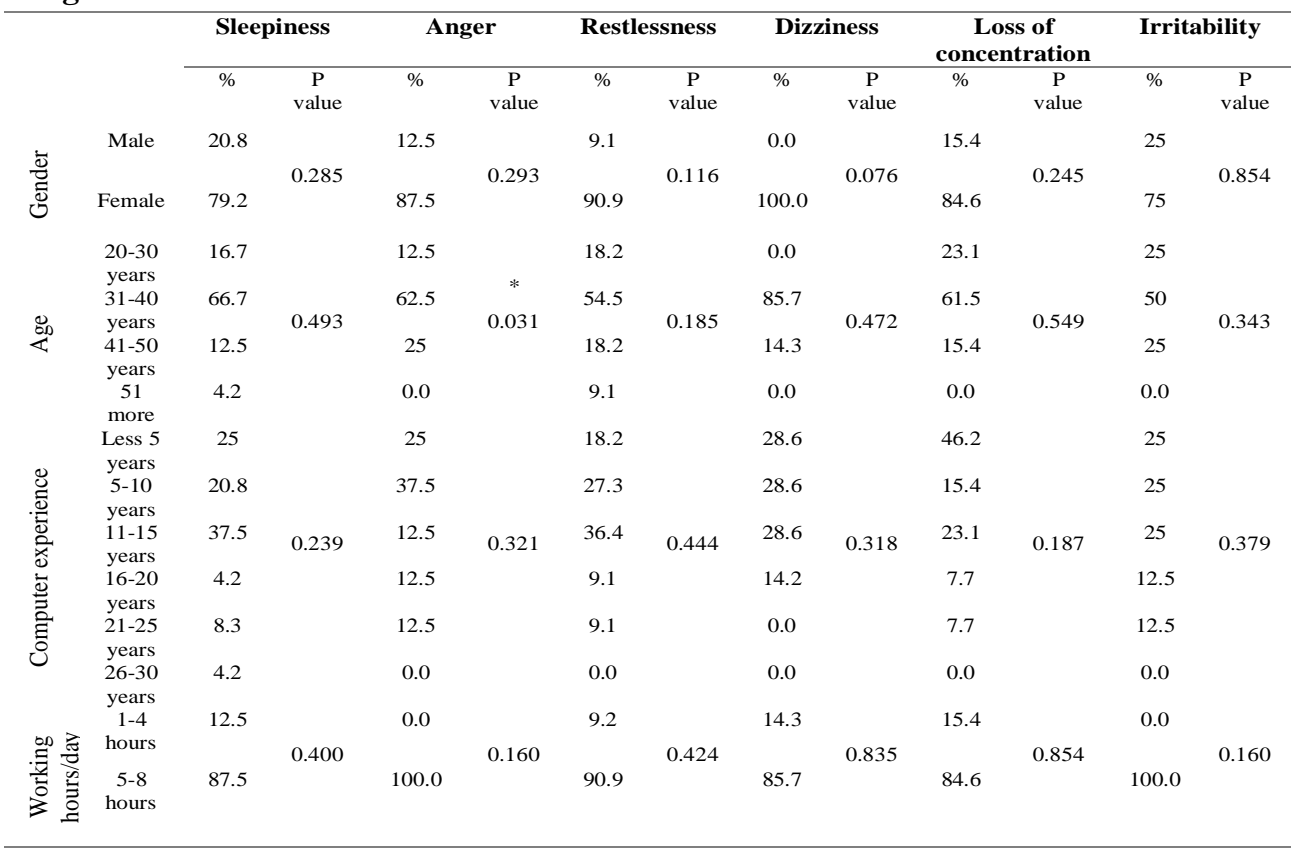

\section{Working Environment \& Equipment}

Working environment and equipment as per the ergonomic standards are important for the health of the worker. The study revealed that $70.2 \%$ of computer monitors are placed at the eye level, whereas $23.4 \%$ were below eye level which was congruent with recommended standards. Although ISO9241 (ISO, 1998) recommended minimum viewing distance as $40 \mathrm{~cm}$, it was reported that majority of the respondents $(40.4 \%)$ change the distance between monitor and seat frequently. Only $19.1 \%$ of the library staff had the monitor at a distance of $50 \mathrm{~cm}$. However, literature revealed that respondents showed greater visual fatigue for viewing distances of $50 \mathrm{~cm}$ rather than 100 $\mathrm{cm}$, and reported that $50 \mathrm{~cm}$ of viewing distance is not sufficient to perform typical computer workstation tasks (Jaschinski et al., 1998).

The majority of the respondents $(61.7 \%)$ were aware of correct sitting posture while working on the computer, whereas $38.3 \%$ were not and used incorrect 
posture causing health problems. The computer monitor of $78.7 \%$ of respondents is directly placed in front of the worker and $89.4 \%$ have placed the mouse next to the keyboard as per the ergonomic standards. The wrist/palm support was not available for $70.2 \%$ of the respondents, whereas $72.3 \%$ were not provided with footrest. $44.7 \%$ of the respondents revealed that the chair used to work in the computer is not adjustable and without good lumbar support (61.7\%) and armrest (53.2\%). However, Smith et al. (2009) reported that chairs should have lumbar support to minimize back strain.

When working on the computer, majority of respondents (46.8\%) take frequent breaks while $31.9 \%$ relax for 1-5 minutes. However, screen filters were not available in computers of $83 \%$ of the respondents.

The workstations of $72.3 \%$ of respondents were adequately lit. Moreover $31.9 \%$ of respondents reported that direct or reflected glare hit on the monitor causing them eye discomforts.

\section{Implications of Workstation Design on Health}

Workstation design affects the working posture which in turn contributes to health related problems. The present study identifies health issues related to computer ergonomics such as musculoskeletal discomforts and visual problems of the library staff due to workstation design and posture. The ChiSquare test proved that there is a significant relationship between the height of the computer desk and pain in the neck $(\mathrm{P}=0.002)$, elbow $(\mathrm{P}=0.014)$, lower $\operatorname{arm}(\mathrm{P}=0.006)$, lower $(\mathrm{P}=0.047)$ and upper $(\mathrm{P}=0.017)$ back (Table 5). When the height of the computer table increases, users are forced to raise arms, elbow and neck and lean forward placing stress on arms and back. A Pearson product-moment correlation was run to determine the relationship between neck pain and computer desk height and reported a positive correlation between neck pain and computer desk height $(r=0.447, \mathrm{P}=0.002, \mathrm{n}=47)$ which revealed that prevalence of pain in the neck increases with an increase of computer desk height.

Prevalence pattern of pain in the shoulder showed a significant relationship with the availability of wrist support $(\mathrm{P}=0.030)$ and disclosed a weak negative correlation $(\mathrm{r}=-0.317, \mathrm{P}=0.03, \mathrm{n}=47)$ which ascertained that shoulder pain decreases with the availability of wrist support. This suggests 
the importance of providing wrist support to computer users to overcome the health issues. Kiss et al. (2012) discovered similar findings and reported that the presence of separate wrist support had a significant relationship with neck and shoulder pain. Although in literature the relationship between computer workstation posture and musculoskeletal discomforts were questioned, present study revealed a significant relationship between lower back pain and posture $(\mathrm{P}=0.034)$ (Table 5).

Furthermore, the Chi-Square test proved that height and distance of the keyboard has a significant relationship with pain in the elbow $(\mathrm{P}=0.003)$, lower back $(\mathrm{P}=0.001)$, and lower arm $(\mathrm{P}=0.008)$ (Table 5). Prevalence pattern of lower arm pain depicted a weak positive correlation with height and distance of keyboard $(\mathrm{r}=0.384, \mathrm{P}=0.008, \mathrm{n}=47)$ and computer desk height $(\mathrm{r}$ $=0.403, \mathrm{P}=0.005, \mathrm{n}=47$ ) which revealed that prevalence of lower arm pain increases with increasing heights and distance of keyboard. Similarly, Sauter et al. (1991) revealed that arm discomforts increased with increased keyboard height.

Table 5: Association between prevalence of musculoskeletal discomfort and workstation design

\begin{tabular}{|c|c|c|c|c|c|c|c|c|c|}
\hline & $\begin{array}{l}\text { Neck } \\
\text { pain }\end{array}$ & $\begin{array}{l}\text { shoulde } \\
\text { r pain }\end{array}$ & $\begin{array}{l}\text { Upper } \\
\text { back } \\
\text { pain }\end{array}$ & $\begin{array}{l}\text { Pain in } \\
\text { elbow }\end{array}$ & $\begin{array}{c}\text { Lower } \\
\text { back } \\
\text { pain }\end{array}$ & $\begin{array}{l}\text { wrist } \\
\text { pain }\end{array}$ & $\begin{array}{l}\text { Pain in } \\
\text { fingers }\end{array}$ & $\begin{array}{c}\text { Muscle } \\
\text { pain }\end{array}$ & $\begin{array}{c}\text { Pain in } \\
\text { lower } \\
\text { arm }\end{array}$ \\
\hline $\begin{array}{l}\text { Location of } \\
\text { monitor }\end{array}$ & 0.865 & 0.829 & 0.840 & 0.347 & 0.086 & 0.759 & 0.418 & 0.757 & 0.578 \\
\hline $\begin{array}{c}\text { View } \\
\text { distance }\end{array}$ & 0.167 & 0.393 & 0.584 & 0.606 & 0.822 & 0.615 & 0.607 & 0.790 & 0.975 \\
\hline Posture & 0.314 & 0.942 & 0.119 & 0.377 & $0.034 *$ & 0.520 & 0.944 & 0.341 & 0.339 \\
\hline $\begin{array}{c}\text { Monitor } \\
\text { placement }\end{array}$ & 0.088 & 0.441 & 0.469 & 0.361 & 0.541 & 0.398 & 0.654 & 0.519 & 0.719 \\
\hline $\begin{array}{l}\text { Height \& } \\
\text { distance of } \\
\text { keyboard }\end{array}$ & 0.170 & 0.514 & 0.069 & $0.003 *$ & $0.001 *$ & 0.706 & 0.278 & 0.172 & $0.008^{*}$ \\
\hline $\begin{array}{c}\text { Mouse } \\
\text { placement }\end{array}$ & 0.426 & 0.345 & 0.824 & 0.685 & 0.903 & 0.532 & 0.850 & 0.483 & 0.764 \\
\hline Desk height & $0.002^{*}$ & 0.739 & $0.017 *$ & $0.014 *$ & $0.047^{*}$ & 0.358 & 0.156 & 0.313 & $0.006^{*}$ \\
\hline $\begin{array}{c}\text { Wrist } \\
\text { support }\end{array}$ & 0.199 & $0.030^{*}$ & 0.421 & 0.534 & 0.978 & 0.775 & 0.480 & 0.875 & 0.297 \\
\hline Chair height & 0.716 & 0.137 & 0.122 & 0.900 & 0.579 & 0.282 & 0.805 & 0.477 & 0.808 \\
\hline $\begin{array}{c}\text { Back } \\
\text { support }\end{array}$ & 0.750 & 0.658 & 0.218 & 0.184 & 0.689 & 0.122 & 0.352 & 0.936 & 0.781 \\
\hline Arm rest & 0.526 & 0.064 & 0.282 & 0.550 & 0.119 & 0.681 & 0.234 & 0.753 & 0.797 \\
\hline
\end{tabular}


The lighting of the computer workstation is vital. Unbalanced levels of light between the computer screen and surrounding will result in visual discomforts. The Chi-Square test proved that there is a significant relationship between double vision with glare $(\mathrm{P}=0.031)$ and light $(\mathrm{P}=0.046)$ (Table 6). The present study revealed a weak positive correlation between glare and double vision $(\mathrm{r}=0.315, \mathrm{n}=47)$. Shantakumari et al. (2014) reported that students using a computer in a very bright or dark room were more prone to visual fatigue symptoms. The present study revealed a weak negative correlation between light levels in the workstation and symptom of double vision $(r=-0.291, n=47)$ which revealed that a decrease of light in the workstation increased double vision.

It revealed that prevalence of blurred vision had a significant relationship with the presence of screen filters $(\mathrm{P}=0.042)$ (Table 6) and a weak negative correlation ( $\mathrm{r}=-0.297, \mathrm{n}=47$ ) between the two which emphasized the importance of the presence of screen filters to reduce blurred vision. Similarly, Adeyemi (2010) also highlighted the importance of having screen protectors in Nigerian libraries.

Reporting pattern of headaches due to prolonged use of computers showed a significant relationship with view distance $(\mathrm{P}=0.003)$ (Table 6) in the present study similar to the findings of Shantakumari et al. (2014). Despite the recommended distance, $40.4 \%$ of respondents were frequently changing the monitor distance which may have resulted in causing headaches. Furthermore, task breaking is vital during continuous work on a computer to reduce eye strain. Relaxing within work was significantly associated with headaches $(\mathrm{P}=0.033)$ due to the prolonged use of computers in the present study which was congruent to the findings of Rahman and Sanip (2011).

Table 6: Association between prevalence of visual discomfort and workstation design

\begin{tabular}{cccccccc}
\hline & $\begin{array}{c}\text { Eye } \\
\text { pain }\end{array}$ & $\begin{array}{c}\text { Double } \\
\text { vision }\end{array}$ & $\begin{array}{c}\text { Blurred } \\
\text { vision }\end{array}$ & Tearing & $\begin{array}{c}\text { Burning } \\
\text { eyes }\end{array}$ & $\begin{array}{c}\text { Dry } \\
\text { eyes }\end{array}$ & Headaches \\
\hline Location of monitor & 0.384 & 0.460 & 0.412 & 0.737 & 0.790 & 0.423 & 0.685 \\
View distance & 0.704 & 0.526 & 0.112 & 0.352 & 0.298 & 0.983 & $0.003^{*}$ \\
Relaxing & 0.476 & 0.595 & 0.762 & 0.126 & 0.431 & 0.277 & $0.033^{*}$ \\
Placement of monitor & 0.513 & 0.283 & 0.491 & 0.720 & 0.100 & 0.530 & 0.743 \\
Screen filter & 0.907 & 0.196 & $0.042^{*}$ & 0.867 & 0.158 & 0.219 & 0.495 \\
Glare & 0.706 & $0.031^{*}$ & 0.808 & 0.326 & 0.555 & 0.414 & 0.133 \\
Light & 0.461 & $0.046^{*}$ & 0.726 & 0.679 & 0.693 & 0.151 & 0.768 \\
\hline
\end{tabular}




\section{Conclusions \& Recommendations}

This study aimed at identifying the computer ergonomics related health issues of library staff of the University of Colombo and to study the implications of the working environment and equipment on health.

The most commonly reported musculoskeletal discomforts due to prolonged computer usage were pain in the neck followed by pain in the shoulder and wrist. Occurrence of all the musculoskeletal discomforts except pain in the elbow were not statistically significant with studied socio-demographic features of gender, age, computer usage hours/ day and computer usage experience. Pain in the eye was the most persistent visual discomfort experienced by respondents followed by headaches. Reporting of eye pain, double vision, blurred vision, tearing, burning eyes and dry eyes had no significant relationship with gender, age, years of computer usage and working hours/day in the context of the study. After prolonged use of computers, major stress related symptom identified was sleepiness while the loss of concentration was identified as the prominent discomfort related to fatigue. However, prevalence of sleepiness, restlessness, dizziness, loss of concentration and irritability did not show any relationship with gender, age, computer experience and working hours/day. Thus, the present study accepts the null hypothesis and concludes that there is no significant relationship between the health problems related to computer ergonomics and sociodemographic characters of the library staff in the present study.

Further, placement of monitors, keyboards and mouse were consistent with the ergonomic standards. It revealed that musculoskeletal discomforts of the neck and pain in the lower arm had a positive correlation with the height of computer table, whereas shoulder pain showed a significant relationship with wrist support. The lighting and glare of the workstation should be adjusted as the study revealed a weak positive correlation between glare and symptoms of double vision. Furthermore, the decrease of light in the workstation tend to increase symptom of double vision in the respondents. Reporting pattern of headaches due to prolonged use of computers showed a significant relationship with view distance and task breaking. To avoid computer vision problems, proper lighting, anti-glare filters, and ergonomic positioning of the computer monitor should be emphasized and regular work breaks should be adhered in the computer workstation, in order to be in par with ergonomic 
requirements. Furthermore, the majority of the respondents were not aware of the view distance they should maintain while working on the computer. It is revealed that to reduce the health problems, library management should organize workstation ergonomics training sessions to provide with knowledge and skills to optimize their workstation configuration, and change behavioural and workstation practices. Furthermore, authorities should provide ergonomically safe working equipment as wrist support, screen filters, adjustable computer tables and ergonomically designed computer chairs to eliminate or reduce the occurrence of computer ergonomics related health disorders.

The current research, being a case at the University of Colombo to identify the Computer ergonomics related health problems of Library staff opens up many opportunities for future research. The present study could thus be extended to all the academic libraries in Sri Lanka for generalizability, theory development and concept validation.

\section{References}

Adeyemi, A. O. (2010). ICT Facilities: Ergonomic Effects on Academic Library Staff. Library Philosophy and Practice.

Asaolu, A. O., \& Itsekor, V. (2014). Ergonomic computer workstation considerations for library staff. International Journal of Academic Library and Information Science, 2(3), 22-26.

Blehm, C., Vishnu, S., Khattak, A., Mitra, S., \& Yee, R. W. (2005). Computer vision syndrome: a review. Surv Ophthalmol, 50(3),253262.

Conlon, C. F., Krause, N., \& Rempel, D. M. (2008). A randomised controlled trial evaluating an alternative mouse and forearm support on upper body discomfort and musculoskeletal disorders among engineers. Occupational and Environmental Medicine, 65(5), 311. https://doi.org/10.1136/oem.2006.032243 
Ellahi, A., Khalil, M. S., \& Akram, F. (2011). Computer users at risk: Health disorders associated with prolonged computer use. Journal of Business Management and Economics, 2(4), 171-182.

Griffiths, K. L., Mackey, M. G., Adamson, B. J., \& Pepper, K. L. (2012). Prevalence and risk factors for musculoskeletal symptoms with computer based work across occupations. Work, 42, 533-541. https://doi.org/10.3233/WOR-2012-1396

ISO (International Organization for Standardization). 1998. Ergonomic Requirements for Office Work with Visual Display Terminals (VDTs) Part 5: Workstation Layout and Postural Requirements (ISO 92415:1998). International Organization for Standardization.

Iwakiri, K., Mori, L., Sotoyama, M., Horiguchi, K., Ochiai, T., Jonai, H., Saito, S. (2004). Survey on visual and musculoskeletal symptoms in VDT workers. Journal of Occupational Health, 46(6), 201-12.

James, C., James, D., Nie, V., Schumacher, T., Guest, M., Tessier, J., Marley, J., Bohatko-Naismith, J., \& Snodgrass, S. (2018). Musculoskeletal discomfort and use of computers in the university environment. Applied ergonomics, 69, 128-135. https://doi.org/10.1016/j.apergo.2018.01.013

Jaschinski, W., Heuer, H. \& Kylian. H.(1998). Preferred position of visual displays relative to the eyes: A field study of visual strain and individual differences. Ergonomics 41 (7): 1034-1049.

Karsh B, Moro F.B.P. \& Smith M.J. (2001). The efficacy of workplace ergonomic interventions to control musculoskeletal disorders: A critical examination of the peer-reviewed literature. Theoret Issues Ergon Sci. 2: 3-96.

Kiss, P., De Meester, M., Kruse, A., Chavée, B., \& Braeckman, L. (2012). Neck and shoulder complaints in computer workers and associated easy to assess occupational factors: a large-scale cross-sectional 
multivariate study. International archives of occupational and environmental health, 85(2), 197-206.

Krejcie, R.V. \& Morgan, D.W. (1970). Determining sample size for research activities. Educational and Psychological Measurement. 30, 607-610.

Marcus, M., Gerr, F., Monteilh, C., Ortiz, D. J., Gentry, E., Cohen, S., Edwards, A., Ensor, C., \& Kleinbaum, D. (2002). A prospective study of computer users: II. Postural risk factors for musculoskeletal symptoms and disorders. American journal of industrial medicine, 41(4), 236-249.

Nwokedi, G. I., Gupiyem,G.G., \& Agbenu, D.O. (2019) Staff awareness of ergonomics principles required at the computer workstation: case study of University of Jos Library. Library Philosophy and Practice. 2723.

Oha, K., Animägi, L., Pääsuke, M., Coggon, D., \& Merisalu, E. (2014). Individual and work-related risk factors for musculoskeletal pain: a cross-sectional study among Estonian computer users. $B M C$ Musculoskeletal Disorders, 15(1), 181. https://doi.org/10.1186/14712474-15-181

Pillai, C. and Jayalatha, K.T (2016). Ergonomics and library professionals-A case study of the University of Kerala. SRELS Journal of Information Management 53: 221.

Rahman, Z. A., \& Sanip, S. (2011). Computer user: demographic and computer related factors that predispose user to get computer vision syndrome. Int J Bus Humanit Technol, 1(2), 84-91.

Rempel, D., Nathan-Roberts, D., Chen, B. Y., \& Odell, D. (2009). The effects of split keyboard geometry on upper body postures. Ergonomics, 52(1), 104-111. 
Sauter, S. L., Schleifer, L. M., \& Knutson, S. J. (1991). Work posture, workstation design, and musculoskeletal discomfort in a VDT data entry task. Human factors, 33(2), 151-167.

Shantakumari, N., Eldeeb, R., Sreedharan, J., \& Gopal, K. (2014). Computer use and vision. related problems among university students in Ajman, United Arab Emirate. Annals of medical and health sciences research, 4(2), 258-263.

Smith, M. J., Carayon, P. \&. Cohen. W. J.(2009). Design of computer workstations. In Human-Computer Interaction Fundamentals, edited by A. Sears and J. A. Jacko, 289-302. Boca Raton, CRC Press.

Suparna K, Sharma A K, Khandekar J.(2005) Occupational health problems and role of ergonomics in information technology professionals in national capital region. Indian J Occup Environ Med,9,111-4

Thomée, S., Härenstam, A., \& Hagberg, M. (2012). Computer use and stress, sleep disturbances, and symptoms of depression among young adults - a prospective cohort study. BMC Psychiatry, 12(1), 176. https://doi.org/10.1186/1471-244X-12-176

Wang, W., Li, C., Zhan, C., \& Long, Y. (1998). Study on the psychological status of video display terminal operator. Journal of hygiene research, 27(4), 233-236. http://europepmc.org/abstract/MED/10682591

Woo, E., White, P., \& Lai, C. (2016). Ergonomics standards and guidelines for computer workstation design and the impact on users' health-a review. Ergonomics, 59(3), 464-475.

Zakerian, S. A., \& Subramaniam, I. D. (2009). The relationship between psychosocial work factors work stress and computer-related musculoskeletal discomforts among computer users in Malaysia. International journal of occupational safety and ergonomics, 15(4), 425-434. 